\title{
Difficulties in the Application of Legitimate Defense and Its Solutions
}

\author{
Wei Gao ${ }^{1, *}$ \\ ${ }^{1}$ Department of Law, School of Law, Humanities and Sociology, WUT, Wuhan, Hubei, China \\ *Corresponding author.Email:1206588409@qq.com
}

\begin{abstract}
In judicial practice, there is a phenomenon of strict application of justifiable defense clauses, which makes this clause a dormant clause. Therefore, it is particularly important to wake up this clause. In judicial practice, we need to define the limits of legitimate defense, correctly identify factors such as the time of defense, and strengthen judicial independence, in order to activate this clause and allow the broad masses of people to dare to exercise legitimate defense.
\end{abstract}

Keywords: Legitimate defense, Defense limit, Defense time, Excessive defense.

\section{THE MAIN PROBLEMS IN THE IDENTIFICAITON OF MY COUNTRY IS LEGITIMATE DEFENSE}

Article 20 of my country's Criminal Law stipulates that for the country, the public interest, the personal, property and other rights of the person or others to be protected from ongoing illegal infringements, the actions taken to stop the illegal infringements will cause harm to the illegal infringers. Proper defense and no criminal responsibility. Correctly understanding the meaning of this law is one of the important prerequisites for the determination of legitimate defense, and it is also a key step. In judicial practice, the judiciary determines that justified defense mainly has the following problems:

\subsection{Legal Professionals Have an Incorrect Understanding of "Obviously Exceeding the Necessary Limit" in the Provisions of the Criminal Law}

Generally speaking, defensive behavior must be within a certain limit, exceeding the necessary limit will constitute excessive defense. [1]In trial practice, some judges failed to understand this clause correctly, and often judged cases that should be considered as legitimate defenses as excessive defenses, making legitimate defenses unable to play their role, prompting the public not to dare to defend themselves, and ultimately leading to This clause became a dormant clause. This problem arises mainly because judges often put equivalence in the first place when judging the limits of defense, while necessity ranks second. Necessity is one of the most important factors in judging justified defense. In short, if an act is a necessary means to stop the illegal infringement, then the act does not exceed the necessary limit, anyway, it may exceed the necessary limit. Necessity is one of the prerequisites for the realization of legitimate defense. If the defender does not use the necessary means of defense, the defender may lose the way to stop illegal infringement, and legitimate defense cannot be implemented. Therefore, to judge whether a behavior constitutes legitimate defense, the necessity of review is the first and most important step. [2]Equivalence means that the defensive behavior must conform to the principle of proportionality, that is, the more serious the illegal infringement, the higher the corresponding degree of defense. On the contrary, the lighter the illegal infringement, the lighter the defense should be. In judicial practice, only equability is often examined, and arbitrarily thinking that exceeding necessity constitutes excessive defense. In the long run, the victim will not dare to resist when he encounters an illegal violation, especially if he resists forcefully, which will lead to the occurrence of the violation. Therefore, in judicial practice activities, legal professionals should put necessity first, judge whether defensive behavior is necessary and the only behavior, and put equivalence in a supplementary position. Only by comprehensive judgment of the two can they correctly understand the 
provisions of the criminal law. The meaning of "necessary limit".

\subsection{Legal Professionals Have Inaccurate Judgments about the Defense Time}

The establishment of legitimate defense requires that defense be timely, and that pre-defense and post-defense are not considered legitimate defenses have been recognized by the academic community. Therefore, it is one of the important factors to judge whether a case constitutes the time for legitimate defense or not. In judicial practice, many legal professionals believe that the time range is narrow, and they mechanically believe that they can only defend themselves when they are being illegally violated. As a result, many cases that should constitute legitimate defense are judged as crimes, which hinders the public's enthusiasm for legitimate defense. Its basic rights cannot be protected. Therefore, the starting point for judging the unlawful infringement should be the immediate danger of the victim's legal interests, and the end criterion is the complete elimination of the danger. [3]If the victim can be defended only when he is being infringed, the victim often loses the best time to position, and the requirements for the victim are too strict to achieve the purpose of the system. Therefore, when the victim's legal interests are facing a more urgent danger, it should be regarded as defense time, and the victim also has plenty of time to defend, and ultimately to achieve legitimate defense. The change in the time for the determination of unlawful infringement can better protect the safety and rights of defenders, and better protect legal interests. Therefore, we cannot require the defender to defend when he is facing the infringement and his legal interests are being infringed. Instead, we should advance appropriately, that is, when the victim's legal interests are in urgent danger, they can defend themselves. On the other hand, the victim should consider the end of defense time only when the danger is completely and completely eliminated. In judicial practice, many cases are judged by the "post-incident perspective", which makes many cases deemed as legitimate defense mistakenly regarded as excessive defense. When judging the time of defense, we should adopt the perspective of ordinary people, that is, from the perspective of the person facing the awake time, rather than the perspective of hindsight. The victim should not be too strict and the victim should not be required to judge the defense time rationally and calmly. The main reason for adopting this identification method is that victims are often nervous when they are in danger, and it is not realistic to make a calm judgment. At the same time, they cannot be overwhelming. The identification standards are too strict, which turns the legitimate defense clause into a "sleeping clause."

\subsubsection{Take the Kunshan Longge Case as an Example to Justify the Defense Time}

In 2018, the Longge anti-kill case occurred in Kunshan City, which became a milestone in the legitimate defense system. The circumstances of the case are as follows: On August 27, 2018, in Kunshan City, a man named "Long Ge" illegally drove a BMW into a non-motorized lane and had a dispute with $\mathrm{Yu}$ Haiming, who was riding an electric car next to him. Afterwards, Long Ge took out a machete from the BMW car and slashed towards Yu Haiming. Both sides hit. Long $\mathrm{Ge}$ accidentally shot down the machete. $\mathrm{Yu}$ Haiming took the machete and slashed towards Long Ge. Long Ge went to the car. Running in the direction, Yu Haiming kept chasing and slashing Long Ge, eventually causing Long Ge to die. A few days later, the Kunshan Public Security Bureau issued an announcement that $\mathrm{Yu}$ Haiming's actions constituted legitimate defense and therefore did not constitute a crime. The most controversial focus in this case is: when Long Ge ran in the direction of the BMW, Yu Haiming still chased and hacked, whether his behavior exceeded the defense time. The traditional view is that: Yu Haiming's behavioral defense is inappropriate and constitutes a crime. [4]Because of this view, Yu Haiming was not in danger at this time, and of course he could not take defensive actions. However, this view uses the "post-event perspective" for judgment. Assuming that we are in the situation at the time, Yu Haiming's ability to recognize and judge must be weakened, and it is impossible to judge the situation rationally and calmly. Even if Long Ge ran to the BMW, the danger Yu Haiming faced was temporarily eliminated, but Long Ge might continue to carry out the harm, and the danger Yu Haiming faced was not completely eliminated. [5]If the behavior is evaluated as an act of harm afterwards, it is unfair. The Long Ge case became a milestone case because the Kunshan police correctly judged the defense time, and then correctly applied the law, obtained a fair result, and protected Yu Haiming's rights.

\subsection{Public Opinion Interferes with Judicial Independence}

In legitimate defense cases, after the defender performs a defensive action, it often results in casualties of the offender.[6] Some of the family members of the offender will describe the case in a way of avoiding the more important, and use television reports, online complaints, and petitions by relevant agencies. These actions often put pressure on the judicial organs and easily arouse public opinion. Therefore, in judicial practice, some judges strictly apply the justifiable defense clause in order to keep things quiet, causing this clause to become a "sleeping clause." Obviously, such a verdict is very unfair to the defenders. Therefore, when applying this clause, we should strictly abide by the 
provisions of the law and make a judgment based on facts in order to achieve the purpose of this clause.

\section{ANALYSIS OF THE MAIN SOLUTION PATH UNDER THE REALISTIC BACKGROUND}

In determining justified defense, legal professionals in our country do not have enough understanding of this clause, and are easily interfered by public opinion in judicial practice. As a result, this clause is less applicable in practice. It is called the "sleeping clause" by many people. It is legal for citizens. Rights cannot be fundamentally guaranteed. It is very urgent to solve this problem in this context. We can solve this problem by improving the professional level of legal professionals and strengthening judicial independence.

\subsection{Strengthen the Professional Adjudication Capabilities of Legal Professionals}

The reason why the legitimate defense system has become a dormant clause is largely due to the lack of professionalism of judges and the inability to correctly determine the defense limits and clarify key conditions such as defense time, which leads to errors in the application of the law and wrong judgments. Therefore, it is particularly important to strengthen the professional level of legal professionals. In order to achieve this goal, we must first improve the professional quality of judges, prosecutors, lawyers and other legal professionals, raise the entry threshold, and strengthen the practical ability training of students majoring in politics and law. At the same time, it is necessary to strengthen the professional guidance of judges and prosecutors, encourage Dohe to study and exchange with outstanding experts, scholars and practitioners, study relevant academic theories, and lay the foundation for future trials. At the same time, the Supreme Court should publish more relevant guiding cases and courts at all levels should also organize more relevant trial learning and exchange meetings to further improve trial capabilities.

\subsection{Strengthen Judicial Independence and Ensure Fair Exercise of Judicial Power}

Another factor that makes the legitimate defense system less applicable in practice is that public opinion tends to interfere with the judiciary, so that judges "dare not" to apply this clause in the trial. The conditions for applying this clause are very strict. Therefore, we should also strengthen judicial independence. In the event of interference in judicial handling, we must dare to give corresponding notifications, pursue investigations, and punish them. On the other hand, we also need to strengthen the judicial staff protection mechanism. Without corresponding laws and regulations, relevant judicial staff must not be punished, so that judges and prosecutors have the confidence to exercise their powers fairly to maintain normal judicial activities. At the same time, it is necessary to punish citizens who interfere in judicial activities and create public opinion and be punished in accordance with the law, and those who constitute a crime shall be investigated for criminal responsibility in accordance with the law. Therefore, we should protect relevant judicial personnel and punish illegal personnel in order to maintain the authority of the courts and enable legal workers to make judgments independently and impartially.

\section{CONCLUSION}

The purpose of the legitimate defense system is to hope that the victim can be brave and dare to fight against illegal infringements to protect their legal rights. However, in the judicial practice of our country, there is often a phenomenon that the application of this system is too strict, which causes this clause to be often called the sleeping clause. Therefore, activating the legitimate defense system is particularly important in today's society. We should improve the professional level of legal professionals, publish more relevant guidance cases, and hold relevant practical trial exchange meetings to ensure the quality of trials. At the same time, we should strengthen the independence of the judiciary, grant judges the power to judge independently, and punish those who create public opinion. Only in this way can this clause be implemented, the purpose of legislation can be realized, and the legal rights of citizens can be protected.

\section{REFERENCES}

[1] Ma Le. "Non-Concession Law" and "Necessary Limits" in my country's Justifiable Defense Clause [J]. "Politics and Laws", 2019(5): 69-79.

[2] Xie Dehai. Analysis on the judicial practice of justifiable defense theory [J]. Theory Monthly, 2008(10): 128-131.

[3] Zhang Kaijun. On the Judgment of the Reality and Urgency of the Unlawful Infringement in Justifiable Defense - Analysis of the Doctrines of Criminal Law in the Yu Haiming Case [J]. "Jiaotong University Law Science", 2019(4): 171-190.

[4] Chen Xuan. The theory of justifiable defense from the perspective of the offender $[\mathrm{J}]$. Legal Studies, 2015(3): 120-138.

[5] Chen Xingliang. The boundary between fighting and defense [J]. Law Science, 2015 (6): 129-137.

[6] Li Xiao Ming. Forty Years of "Justifiable Defense": "Yu Huan Case" Reflects the Amendment of Article 20 of the Criminal Law [J].Hebei Law, 2020(4): 46-63. 